\title{
Epidemiology of Anemia at the Internal Medicine Department in Borgou Departmental Hospital Center (DHC) in Parakou (Benin)
}

\author{
Comlan Albert Dovonou1,2, Adébayo Alassani ${ }^{2 *}$, Cossi Angelo Attinsounon ${ }^{1,2}$, Serge Ade ${ }^{1,2}$, \\ Kadidjatou Sake1,2, Jivaterd Degla ${ }^{2}$, Séraphin Ahoui ${ }^{2}$, Moïse Adegbindin ${ }^{2}$, Prosper Gandaho ${ }^{1}$, \\ Djimon Marcel Zannou ${ }^{3}$, Fabien Houngbe ${ }^{3}$, Isidore Zohoun ${ }^{3}$
}

\author{
${ }^{1}$ Medicine Department and Medical Specialities, Medical Faculty, Parakou University, Parakou, Benin \\ ${ }^{2}$ Internal Medicine Department, Borgou Departmental Teaching Hospital, Parakou, Benin \\ ${ }^{3}$ Medicine Department and Medical Specialities of Cotonou Health Science, Parakou, Benin \\ Email: *adebayoalassani@gmail.com
}

How to cite this paper: Dovonou, C.A., Alassani, A., Attinsounon, C.A., Ade, S., Sake, K., Degla, J., Ahoui, S., Adegbindin, M., Gandaho, P., Zannou, D.M., Houngbe, F. and Zohoun, I. (2018) Epidemiology of Anemia at the Internal Medicine Department in Borgou Departmental Hospital Center (DHC) in Parakou (Benin). Open Journal of Internal Medicine, 8, 123-130. https://doi.org/10.4236/ojim.2018.82013

Received: February 12, 2018

Accepted: March 31, 2018

Published: April 3, 2018

Copyright $\odot 2018$ by authors and Scientific Research Publishing Inc. This work is licensed under the Creative Commons Attribution International License (CC BY 4.0).

http://creativecommons.org/licenses/by/4.0/ (c) (i) Open Access

\begin{abstract}
Objective: To describe clinical and biological characteristics of anemia in the Internal Medicine department of Borgou Departmental Hospital Center (DHC). Methods: This was a transversal and descriptive study for an analytic purpose. All patients hospitalized in the Internal Medicine department of Borgou DHC who had a hemogram for their care were included in the study. Anemia was defined as a hemoglobin level lower than $12 \mathrm{~g} / \mathrm{dL}$ for men and lower than $11.5 \mathrm{~g} / \mathrm{dL}$ for women. Results: Frequency of anemia was $61.8 \%$ (76 of 123 patients). Anemia was moderate in $47.4 \%$ of the cases and severe in $27.6 \%$ of the cases. Basing on the mean corpuscular volume, microcytic anemia accounted for $36.8 \%$, anemia was normocytic in $46.1 \%$ and macrocytic in $17.1 \%$ of cases. According to the mean corpuscular hemoglobin concentration, normochromic anemia accounted for $81.6 \%$ of the series and hypochromic in $18.4 \%$. The most common pathologies found in anemic patients came from digestive origin (17\%), the renal causes were also found in $17 \%$ of the cases. Cardiac pathologies were responsible for anemia in $13 \%$ of cases. Malaria and pulmonary pathologies were responsible for anemia in respectively $12 \%$ and $9 \%$. The main factors associated with anemia were young age (young adult) and neurological pathologies. Conclusion: Anemia hospital prevalence is very high in the Internal Medicine Department of Borgou DHC. Awareness of populations and practitioners for the early management of various pathologies which provide anemia could improve this presentation.
\end{abstract}

\section{Keywords}

Anemia, Internal Medicine, Parakou 


\section{Introduction}

Anemia is a public health problem according to World Health Organisation. Anemia is defined as a condition in which there is less than the normal hemoglobin $(\mathrm{Hb})$ level in the body, which decreases oxygen-carrying capacity of red bloodcells to tissues. World Health Organization (WHO) definitions for anemia differ by age, sex and pregnancystatus as follows: children 6 months to 5 year anemia is defined as a $\mathrm{Hb}$ level $<11 \mathrm{~g} / \mathrm{dl}$, children $5-11$ years $\mathrm{Hb}<11.5 \mathrm{~g} / \mathrm{dl}$, adult males $\mathrm{Hb}<13 \mathrm{~g} / \mathrm{dl}$; nonpregnant women $\mathrm{Hb}<12 \mathrm{~g} / \mathrm{dl}$ and pregnant women $\mathrm{Hb}<11 \mathrm{~g} / \mathrm{dl}$. Anemia could be classified as mild, moderate and severe. The $\mathrm{Hb}$ level for each class of anemia in pregnancy are $10.0-10.9 \mathrm{~g} / \mathrm{d} 1$ (mild), 7 - $9.9 \mathrm{~g} / \mathrm{dl}$ (moderate) and $<7 \mathrm{~g} / \mathrm{dl}$ (severe) [1] [2] [3]. In fact, Anemia is associated with a high rate of morbidity and mortality [4] [5]. More than two milliard people are affected in the world with a high share in developing countries [6] [7] [8]. Thirty three percent (32.9\%) of the world population were anemic in 2010 [1]. In hospitalized patients, this prevalence varies between $40 \%$ and 50\% [9]. Anemia has many effects on individual health like a reduction in the productivity and the physical capacity [10] [11]. It is also linked to the elevation of morbidity in hospital. Anemia may be due to a single factor such as a nutritional deficiency or its cause may be multifactorial. Anemia results from one or more of the following events: loss of red blood cells, reduction in the production of red blood cells, increased destruction of red blood cells, and shorter life span of red blood cells. Multiple factors may contribute to the development of complex anemia in hospitalized patients, including nutritional deficiencies, suppression of RBC production bymedications, inflammatory cytokines (inflammatory anemia or anemia of chronic disease), and chronic or acute bleeding [12]. In northern Benin, the problem extent is unknown. The goal of this study was to describe anemia clinical and biological characteristics in the Internal Medicine Department of Borgou Departmental Hospital Center.

\section{Patients and Methods}

This transversal and descriptive study is aimed at analyzing with a prospective data collectioncovering the period between the 1 st January 2017 and 31st March 2017. The inclusion criteria were: to be over 15 years of age, to be hospitalized in the Internal Medicine Department, having performed a hemogram and to have provided their informed consent to participate in the study. The data collection was conducted via a questionnaire and a medical examination record elaborated for this purpose. The questionnaire contained sociodemographic characteristics, clinical and biological characteristics of the patients.

Anemia has been defined as a hemoglobin level under $12 \mathrm{~g} / \mathrm{dL}$ in men and under $11.5 \mathrm{~g} / \mathrm{dL}$ in women. The severity of the anemia has been assessed according to the following degrees: mild when hemoglobin level is at $10 \mathrm{~g} / \mathrm{dL}$ or higher, moderate when the hemoglobin level is less than $10 \mathrm{~g} / \mathrm{dL}$ and superior or equal to $7 \mathrm{~g} / \mathrm{dL}$, severe when the haemoglobin level is less than $7 \mathrm{~g} / \mathrm{dL}$ andde- 
compensated when the haemoglobin level is inferior to $7 \mathrm{~g} / \mathrm{dL}$ and the patient has at least one sign of intolerance. The anemia is normocytic if the mean corpuscular volume (MCV) is between 80 and $90 \mathrm{fL}$, microcyticif MCV is inferior to $80 \mathrm{fL}$ and macrocyticif MCV is higher than $90 \mathrm{fL}$. The anemia is normochromicifthe mean corpuscular hemoglobin concentration (MCHC) is between 30 and $36 \mathrm{~g} / \mathrm{dL}$ and/or the Mean corpuscular hemoglobin $(\mathrm{MCH})$ is between 25 and 32 $\mathrm{pg}$, hypochromicifthe MCHC is lower than $30 \mathrm{~g} / \mathrm{dL}$ and/or $\mathrm{MCH}$ is inferiorto 25 pg. According to the Body Mass Index (BMI) the three following classes have been retained: normal if $\mathrm{BMI}$ is between 18.5 and $25 \mathrm{~kg} / \mathrm{m}^{2}$, over weight if $\mathrm{BMI}$ is superiorto $25 \mathrm{~kg} / \mathrm{m}^{2}$ and thin orcachectic if BMI is under $18.5 \mathrm{~kg} / \mathrm{m}^{2}$. The softwares EPI INFO version 3.5.3. and Epi-7 have been used for the processing and analysis of the data. The statistical tests Chi-square and z-score transformation have been used to investigate the significance level of the suspected associations between the study factors.

\section{Results}

\subsection{Sociodemographic Characteristics}

The average age of the anemic patients was $40.62 \pm 16.91$ years with the extremes 16 years and 92 years. The median age was 39 years. Whereas the average age of the non-anemic patients was $49.19 \pm 18.81$ with the extremes 21 and 85 years and the median age was 45 years. Out of 123 patients included in this study, 68 were male. Ninety three were married, a prevalence of $75.60 \%$; 76 patients came from Parakou, 18 lived more than $10 \mathrm{~km}$ from Parakou and 29 came from others departments of Benin or from the neighbouring countries.

\subsection{Clinical and Biological Characteristics}

Seventy eight patients had a normal nutritional status, 26 were under nourished and 19 were overweight out of 123 patients included in the study; 76 suffered from anemia, or a prevalence at $61.8 \%$.

According to the anemia severity, 19 patients (25\%) had mild anemia, 36 (47.4\%) suffered from moderate anemia, 21 (27.6\%) from severe anemia and 8 (10.5\%) from decompensated anemia.

According to the type of anemia, using the MGV for the classification: microcytic anemia represented $36.8 \%$, normocytic anemia $46.1 \%$ and macrocytic anemia accounted for $17.1 \%$. On the basis of the MCHC: The normochromic anemia represented $81.6 \%$ and hypochromic anemia $18.4 \%$.

The pathologies most encountered in anemic patients are digestives pathologies (17\%), the nephropathies (17\%), cardiac pathologies (13\%), malaria $(12 \%)$ and pulmonary pathologies (9\%).

\subsection{Risk Factors Associated with Anemia}

Sex was not associated with anemia.

The younger age was associated with anemia $(p=0.043)$ (Table 1$)$. 
Table 2 and Table 3 show respectively anemia prevalence according to the nutritional status and the diagnosis on leaving. The nutritional statuts was not associated with anemia (Table 2). According to the diagnosis on leaving, neurological pathologies were associated with anemia (Table 3).

\section{Discussion}

The lack of technical capacity means didn't allow to determine the reticulocyte rate in order to identify a regenerative or a non-regenerative anemia and the small sample of echantillon. This study allowed the description of anemia epidemiology according to the conditions for exercisingin the developing countries like Benin.

Table 1. Patients distribution by age.

\begin{tabular}{|c|c|c|c|}
\hline Age (years) & Anemic Patients n (\%) & Non-anemic Patients n (\%) & $p$ \\
\hline$[16-20]$ & $6(100)$ & $0(0)$ & \\
\hline$[21-40]$ & $35(64.8)$ & $19(35.2)$ & \\
\hline$[41-60]$ & $26(63.4)$ & $15(36.6)$ & 0.043 \\
\hline 61 et more & $9(40.9)$ & $13(59.1)$ & \\
\hline
\end{tabular}

Table 2. Patients distribution by the nutritional condition.

\begin{tabular}{ccccc}
\hline & Size & $\begin{array}{c}\text { Anemic } \\
\text { Patients n (\%) }\end{array}$ & $\begin{array}{c}\text { non-anemic } \\
\text { Patients n (\%) }\end{array}$ & $p$ \\
\hline Normal & 78 & $45(57.7)$ & $33(42.3)$ \\
Weight loss and cachexia & 26 & $20(76.9)$ & $6(23.1)$ & 0.213 \\
Overweight & 19 & $11(57.9)$ & $8(42.1)$ \\
\hline
\end{tabular}

Table 3. Anemia prevalencebythe retained diagnostic on leaving.

\begin{tabular}{ccccc}
\hline & Size & $\begin{array}{c}\text { Anemic Patients n } \\
(\%)\end{array}$ & $\begin{array}{c}\text { Non-anemic Patients n } \\
(\%)\end{array}$ & $p$ \\
\hline Digestive pathologies & 24 & $17(70.8)$ & $7(29.2)$ & 0.357 \\
Malaria & 20 & $12(60.0)$ & $8(40.0)$ & 1.000 \\
Pulmonarypathologies & 13 & $9(69.2)$ & $4(30.8)$ & 0.764 \\
Sepsis & 7 & $6(85.7)$ & $1(14.3)$ & 0.249 \\
Opportunistic infections & 8 & $5(62.5)$ & $3(37.5)$ & 1.000 \\
Neoplasia & 5 & $5(100)$ & $0(0)$ & 0.155 \\
Blood diseases & 6 & $5(83.3)$ & $1(16.7)$ & 0.405 \\
Neurological diseases & 24 & $21(87.5)$ & $3(12.5)$ & $p<0000$ \\
Others & 18 & $9(50.0)$ & $9(50.0)$ & 0.533
\end{tabular}


Among the main causes of hospitalization in Benin, Anemia was in second position (12.3\%) aftermalaria (32.2\%) [13]. Adingni reported a hospital frequency at $25.4 \%$ in Cotonou [14]. The anemia frequency in the internal department of Borgou DHC was $61.8 \%$. That very high frequency was due to our study method. Over 3 months period, we realized a complete blood count in all the patients hospitalized in the service without prejudice of the reason for hospitalization. That method allowed us to diagnosis a larger number of anemic patients even the subclinical cases. That frequency is superior to $25.4 \%$ reported by Adingni [14] in Cotonou during a retrospective study on the records of the patients registered as the ones suffering from anemia in CNHU-HKM internal medicine department in Cotonou from 2006 to 2010. The high frequency of anemia in internal medicine department of Borgou DHC could be also justified by the fact that hospitalized patients come from several specialities: Nephrology, Cardiology and Infectiology. Shill [3] and Terrier [15] have reported a similar prevalence at respectively $53.3 \%$ and $65 \%$. In people living with $\mathrm{HIV}, 44 \%$ of them are anemic in Tanzania. In Bangladesh, 32\% of patients suffering from pulmonary diseases are anemic [16]. In United States, the prevalence of anemia in hospitalized patients is low at $22.8 \%$ [12]. That variance is due to socio-economic difference between developed countries and the developing ones [1].

The number of the patients suffering from a mild anemia was $19(25 \%)$. The ones who had a moderate anemia were $36(47.4 \%)$ and $21(27.6 \%)$ had a severe anemia. Adingni [14] reported a higher number of severe anemia (40.4\%), followed by mild anemia (31.4\%) and moderate anemia (28.2\%). In Maroc, El Hioui et al. [17] rather noted in their series that almost half of the investigated patients (45\%) had a hemoglobin level inferior to $6.5 \mathrm{~g} / \mathrm{dL}$.

Classifying anemia according to MGV, microcytic anemia represented $36.8 \%$, normocytic anemia at $46.1 \%$ and macrocytic anemia represented $17.1 \%$. According to Adingni [14], microcytic anemia represented 30.4\%, normocytic anemia $40.8 \%$ and macrocytic anemia $28.8 \%$. According to El Hioui et al. [17] microcytic anemia represented $39 \%$ followed by macrocytic anemia $37.8 \%$ andnormocytic anemia $23.2 \%$.

On the basis of the MCHC, normochromic anemia represented $81.6 \%$ and hypochromic anemia $18.4 \%$. Adingni [14] found the same generaltrend: $54.6 \%$ of normochromic anemiaand $45.4 \%$ of hypochromic anemia. According to Sellam et al. [10], hypochromic anemia was the more frequent (88.6\%) than normochromic anemia (11.4\%).

In our series, the pathologies found in anemic patients were digestive pathologies (22.4\%), nephropathies (22.4\%), cardiac pathologies (17\%) and malaria $(15.8 \%)$. The high rate of nephropathies found in ours sample could be explained by the fact that in Borgou DHC, nephrology is attached to internal medicine department. According to Diallo et al. [18] in Mali, the pathologies most often encountered were tuberculosis (21.8\%), livercirrhosis (14.3\%) anddiabetes $(7.5 \%)$. But his study was on people living with HIV. In Cotonou and Parakou, hepato-digestive pathologies and HIV infection are encountered in 
anemic patients. The factors associated with anemia were young age neurological pathologies. Sellam and et al., Leite et al. and Makubi et al. have reached the same association [8] [10] [19]. This association between anemia and youngest patients could be explained by the lower average of the anemic patients. In this study, the average age of the anemic patients was $40.62 \pm 16.91$ years where as the one of the non-anemic was $49.19 \pm 18.81$ years. Adingni, El Hioui et al. have reported a similar average age with respectively 42.8 years and $41 \pm 18.33$ years [14] [17]. Anani and al [20] confirmin their studies at the Blood Diseases Department that most of the anemic patients (74.6\%) were under 40 years old. Whereas according to Bach et al. and Pilgrim et al. studies, anemia prevalence is higher in the old patients [4] [21].

Patients suffering from neurological problems are more anemic. The loss of autonomy and the alteration of consciousness could explain that association.

\section{Conclusion}

The frequency of anemia is high in the internal medicine department at Borgou DHC. Normocytic, normochromic and moderate anemia are the most encountered. The pathologies encountered the most in anemic patients were digestive, renal, cardiac, pulmonary and infectious and especially malaria. Awareness of populations and practitioners for early health care of the pathologies that create anemia could improve this presentation in order to avoid its harmful effects.

\section{References}

[1] Nicholas, J.K., Rashmi, J., Mohsen, N., Sarah, K.W., Nicole, J., Rafael, L., et al. (2014) A Systematic Analysis of Global Anemia Burden from 1990 to 2010. Blood, 123, 615-624. https://doi.org/10.1182/blood-2013-06-508325

[2] Koum, D.K., Tsakeu, E.N.D., Sack, F.N., Ngalagou, P.T.M., Kamanyi, A. and Mandengue, S.H. (2014) Aspects cliniques et biologiques des anémies pédiatriques dans un hôpital de District urbain au Cameroun. Pan African Medical Journal, 16, $1-6$.

[3] Shill, K.B., Karmakar, P., Kibria, G., Das, A., Rahman, M.A., Hossain, M.S., et al. (2014) Prevalence of Iron-Deficiency Anaemia among University Students in Noakhali Region, Bangladesh. Journal of Health, Population and Nutrition, 32, 103-110.

[4] Bach, V., Schruckmayer, G., Sam, I. and Kemmler, G. (2014) Prevalence and Possible Causes of Anemia in the Elderly: A Cross-Sectional Analysis of a Large European University Hospital Cohort. Clinical Interventions in Aging, 9, 1187-1196.

[5] Geisel, T., Martin, J., Schulze, B., Schaefer, R., Bach, M., Virgin, G., et al. (2014) An Etiologic Profile of Anemia in 405 Geriatric Patients. Anemia, 1, 320-326.

[6] Ramzi, M., Haghpanah, S., Malekmakan, L., Cohan, N., Baseri, A., Alamdari, A., et al. (2011) Anemia and Iron Deficiency in Adolescent School Girls in Kavar Urban Area, Southern Iran. Iranian Red Crescent Medical Journal, 13, 128-133.

[7] Uddin, M.K., Sardar, M.H., Hossain, M.Z., Alam, M.M., Bhuya, M.F., Uddin, M.M., et al. (2010) Prevalence of Anaemia in Children of 6 Months to 59 Months in Narayanganj, Bangladesh. Journal of Dhaka Medical College, 19, 126-130.

[8] Leite, M.S., Cardoso, A.M., Coimbra, E.A., Welch, J.R., Gugelmin, S.A., Lira, P.C.I., 
et al. (2013) Prevalence of Anemia and Associated Factors among Indigenous Children in Brazil: Results from the First National Survey of Indigenous People's Health and Nutrition. Nutrition Journal, 12, 1-11.

[9] Petrosyan, I., Blaison, G. and Andrés, E. (2012) Anaemia in the Elderly: An Aetiologic Profile of a Prospective Cohort of 95 Hospitalised Patients. European Journal of Internal Medicine, 23, 524-552. https://doi.org/10.1016/j.ejim.2012.03.013

[10] Sellam, E.B. and Bour, A. (2014) Anémie chez les femmes en âge de procréer au Maroc (Préfecture d'Oujda-Angad). Antropo, 32, 35-44.

[11] Elzen, W.P.J., Willems, J.M., Westendorp, R.G.J., De Craen, A.J.M., Assendelft, W.J.J. and Gussekloo, J. (2009) Effect of Anemia and Comorbidity on Functional Status and Mortality in Old Age: Results from the Leiden 85-Plus Study. Canadian Medical Association Journal, 181, 151-157. https://doi.org/10.1503/cmaj.090040

[12] Kurniali, P.C., Curry, S., Brennan, K.W., Velletri, K., Shaik, M., Schwartz, K.A., et al. (2014) A Retrospective Study Investigating the Incidence and Predisposing Factors of Hospital-Acquired Anemia. Anemia, 1, 402-407.

[13] Kora, B.T., Akpamoli, A., Finoude, M., Amoussou, R.K., Acakpo, S.A., et al. (2010) Annuaire des statistiques sanitaires. Ministère de la Santé; République du Bénin.

[14] Adingni, C. (2011) Description des anémies observées dans le service de Médecine Interne du CNHU-HKM. Thèse de doctorat en médecine; Faculté des Sciences de la Santé de Cotonou; Université d'Abomey-Calavi (Bénin), 1591, 69.

[15] Terrier, B., Resche-Rigon, M. and Andres, E. (2012) Prevalence, Characteristics and Prognostic Significance of Anemia in Daily Practice. QJM, 105, 345-354. https://doi.org/10.1093/qjmed/hcr230

[16] Ahmed, N., Parvin, R. and Azad, A.K. (2014) Anemia in Patients with Chronic Obstructive Pulmonary Disease in a Tertiary Care Hospital in Bangladesh. Journal of Enam Medical College, 4, 151-155. https://doi.org/10.3329/jemc.v4i3.20943

[17] El Hioui, M., Ahami, A., Aboussaleh, Y., Lemrini, J. and Loutfi, H. (2006) Anémie en milieu hospitalier marocain: Typologie et influences des facteurs sociodémographiques sur son incidence. Antropo, 12, 83-91.

[18] Diallo, D., Baby, M., Dembele, M., Keita, A., Sidibe, A.T., Cisse, I.A., et al. (2003) Fréquence, facteurs de risque et valeur pronostique de l'anémie associée au VIH/sida chez l'adulte au Mali. Bulletin De La Societe De Pathologie Exotique, 96, 123-127.

[19] Makubi, A.N., Mugusi, F., Magesa, P.M., Roberts, D. and Quaresh, A. (2012) Risk Factors for Aneamia among HIV Infected Children Attending Care and Treatment Clinic at Muhimbili National Hospital in Dar es Salaam, Tanzania. Tanzania Journal of Health Research, 14, 1-9. https://doi.org/10.4314/thrb.v14i1.11

[20] Anani, L.Y., Houssou, B., Massi, M.R., Sagbohan, V., Dèhoumon, J. and Latoundji, S. (2012) Evaluation de la démarche diagnostique des anémies dans la ville de Cotonou. Journal de la société de Biologie clinique, 17, 61-71.

[21] Pilgrim, T., Vetterli, F., Kalesan, B., Stefanini, G.G., Raber, L., Stortecky, S., et al. (2012) The Impact of Anemia on Long-Term Clinical Outcome in Patients Undergoing Revascularization with the Unrestricted Use of Drug-Eluting Stents. Circulation: Cardiovascular Interventions, 5, 202-210. https://doi.org/10.1161/CIRCINTERVENTIONS.111.965749 


\section{Appendix}

\section{Data Collection Sheet}

Name

Age (years)

Sex

Ethnicity

Religion

Profession

Marital status

Education

Residence

Weight (kg)

Height (m)

Body Mass Index

Diabetes mellitus

Hypertension

Yes No

Sickle cell disease

Yes

No

HIV

Yes

No

Chronic kidney failure

Yes

No

Tobacco use

Yes No

Alcohol intake

Yes

No

Reason for consultation

Yes

No

Functional signs

Condition

State of consciousness

Respiratory rate

Pulse

Blood pressure

Diagnosis retained:

Hemogram data:Hemoglobin level

- $\mathrm{MCV}$

- $\mathrm{MCHC}$ 